\title{
Objective assessment of surgical operative performance by observational clinical human reliability analysis (OCHRA): a systematic review
}

\author{
Benjie Tang ${ }^{1}$ (D) Alfred Cuschieri ${ }^{2}$
}

Received: 28 November 2019 / Accepted: 24 December 2019 / Published online: 17 January 2020

(c) The Author(s) 2020

\begin{abstract}
Background Both morbidity and mortality data (MMD) and learning curves (LCs) do not provide information on the nature of intraoperative errors and their mechanisms when these adversely impact on patient outcome. OCHRA was developed specifically to address the unmet surgical need for an objective assessment technique of the quality of technical execution of operations at individual operator level. The aim of this systematic review was to review of OCHRA as a method of objective assessment of surgical operative performance.

Methods Systematic review based on searching 4 databases for articles published from January 1998 to January 2019. The review complies with Preferred Reporting Items for Systematic reviews and Meta-Analyses (PRISMA) guidelines and includes original publications on surgical task performance based on technical errors during operations across several surgical specialties.

Results Only 26 published studies met the search criteria, indicating that the uptake of OCHRA during the study period has been low. In $31 \%$ of reported studies, the operations were performed by fully qualified consultant/attending surgeons and by surgical trainees in $69 \%$ in approved training programs. OCHRA identified 7869 consequential errors (CE) during the conduct of 719 clinical operations (mean =11 CEs). It also identified 'hazard zones' of operations and proficiency-gain curves (P-GCs) that confirm attainment of persistent competent execution of specific operations by individual trainee surgeons. P-GCs are both surgeon and operation specific.

Conclusions Increased OCHRA use has the potential to improve patient outcome after surgery, but this is a contingent progress towards automatic assessment of unedited videos of operations. The low uptake of OCHRA is attributed to its laborintensive nature involving human factors (cognitive engineering) expertise. Aside from faster and more objective peer-based assessment, this development should accelerate increased clinical uptake and use of the technique in both routine surgical practice and surgical training.
\end{abstract}

Keywords Observational clinical human reliability analysis (OCHRA) - Objective assessment of surgical operative performance $\cdot$ Technical error $\cdot$ Task performance $\cdot$ Hazard zones of operations $\cdot$ Proficiency-gain curves

Traditionally, the quality of surgery is assessed on morbidity and mortality data (MMD) [1,2]. Useful as it is in hospital surgical practice, the limitation of MMD as a performance

Benjie Tang

b.tang@dundee.ac.uk

$1 \quad$ Surgical Skills Centre, Ninewells Hospital and Medical School, Level 5, School of Medicine, University of Dundee, Dundee DD1 9SY, Scotland, UK

2 Institute for Medical Science and Technology, School of Medicine, University of Dundee, Dundee, Scotland, UK index, is its retrospective nature. Learning curves (LC) are often used by surgeons who are 'learning' (i.e., gaining proficiency) in the execution of an operation, as performance improves with increasing experience [3-6].

Neither MMD nor LCs can provide objective information on the nature of intraoperative errors and their mechanisms when these effect adversely patient outcome. Specifically, they fail to differentiate the exact role of technical errors from other components of surgical competence, e.g., nontechnical skills [7-10], or the level of proficiency of surgeons by proficiency-gain curves (P-GCs) (Fig. 1). The $\mathrm{P}-\mathrm{GC}$ of an individual surgeon for an operation represents 
Fig. 1 PRISMA guidelinesbased selection of publications for systemic reviews
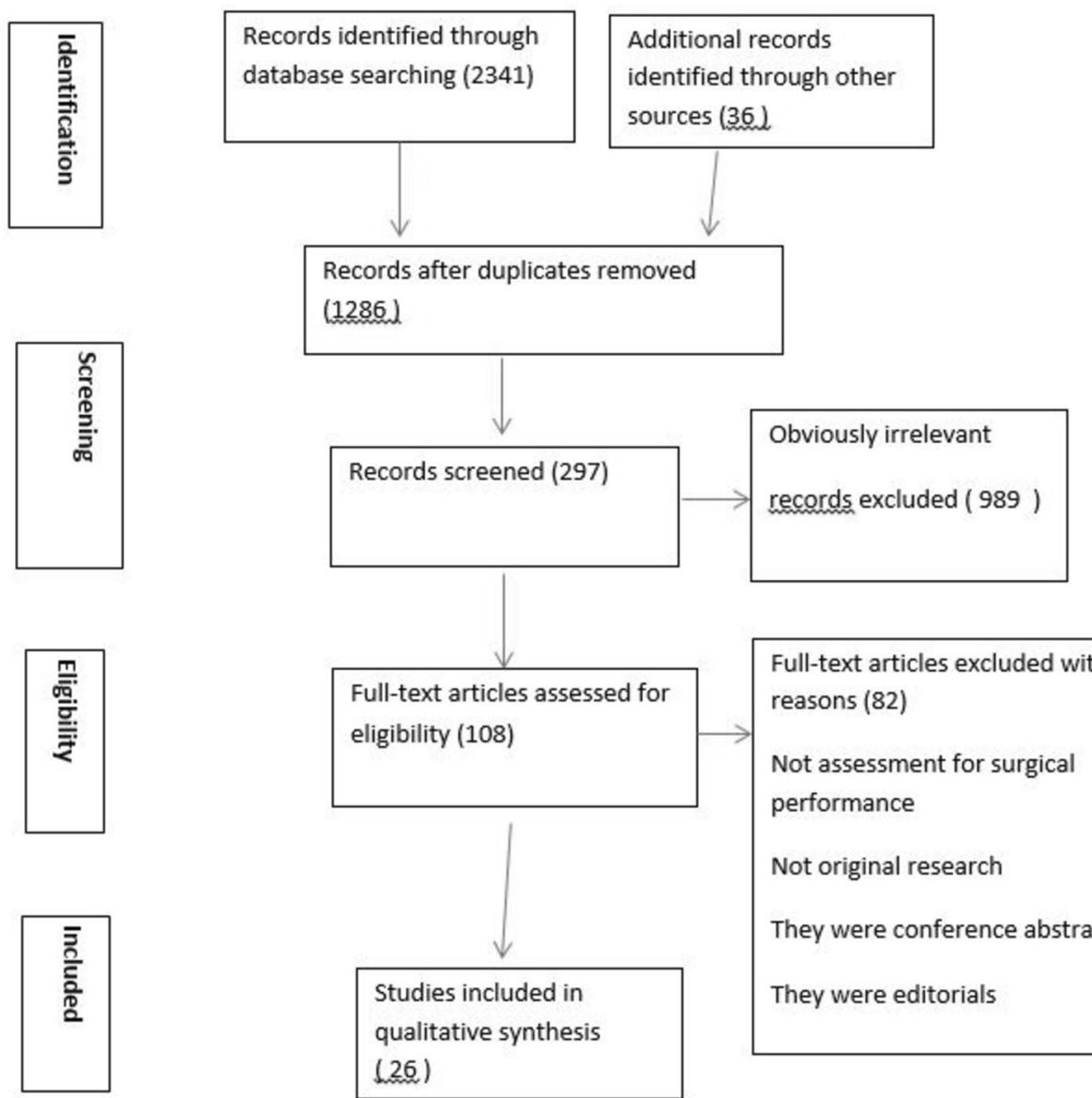

Full-text articles excluded with
reasons (82)
Not assessment for surgical
performance
Not original research
They were conference abstracts
They were editorials

(26)

The first study to use of HRA techniques in laparoscopic surgery was published in 1998. It analyzed the surgical task performance based on technical errors during laparoscopic cholecystectomy (L chole) [15]. Subsequent research from the Surgical Skills Unit in Dundee was directed towards increasing the clinical relevance of HRA. This was necessary as HRA is essentially predictive, i.e., its objective being to ensure that the activity, e.g., civilian flight, space flight etc., is as safe as is humanly possible before the aircraft takes off. In sharp contrast, all operations can nowadays be assessed objectively from an unedited video recording using established human factors (cognitive) engineering expertise. This approach renders HRA observational and specific to an operator. Hence this modified HRA is referred to as 'Observational Clinical - Human Reliability Assessment (OCHRA) [16, 21-42]. The purpose of this review was to analyze the current state, uptake and limitations of the use of OCHRA to assess intraoperative technical errors, hazard zone of operations and proficiency-curves of operations. 


\section{Methods}

\section{Search strategy and criteria}

The review was performed using the guidelines outlined in Systematic Reviews and Meta-Analyses (PRISMA) statement (Fig. 1) [43]. Only publications related to assessment of surgical task performance and surgical operations by identifying technical errors using HRA and OCHRA were included across specialties: General Surgery, Colorectal Surgery, Bariatric Surgery, Urology, Ophthalmic Surgery, Pediatric Surgery, and Otorhinolaryngology. Surgical tasks in surgical training programs and surgical performance in experimental surgical studies were also included. Exclusions were publications on non-surgical performance, descriptive publications without data, conference abstracts, letters, editorials and commentaries, and non-English publications.

Since this study was a systematic review and there were no human subjects involved, thus, the institutional review board (IRB) approval and written consent were not required.

\section{Eligibility criteria}

An initial search was carried out on PubMed, EMBASE, Web of Science and the Cochrane Library for English language articles published from January 1998 to January 2019. Search strategy and terms used included 'human reliability analysis (HRA),' 'observational clinical human reliability analysis (OCHRA), 'human error in surgery,' 'adverse events,' 'human error identification,' 'technical error in surgery,' 'surgical performance,' 'task analysis in surgery,' and 'competency assessment.' A further search used terms such 'patient safety,' 'hazard zones in surgery,' 'human factors in surgery,' 'proficiency-gain curves in surgery,' 'surgical skills training.' All the key search terms were combined subsequently.

The culled publications were retrieved in full text for further assessment for eligibility. Following review, relevant references cited in the included articles were also retrieved and scrutinized.

\section{Data extraction and synthesis}

Studies describing use of HRA or OCHRA for direct assessment of surgical operations were grouped together. Other publications in which HRA or OCHRA were used as one of the methods to assess surgical task performance for research projects were grouped separately. Microsoft
Excel 2016 (Microsoft Corp, Redmond, WA) was used to manage the extracted data. Risk of bias within individual or across studies was not specifically assessed.

\section{Assessment of methodological quality}

The Medical Education Research Study Quality Instrument (MERSQI) [44] was applied to assess the quality of studies conducted using OCHRA. The MERSQI contains 10 items that reflect 6 domains of study quality including study design, sampling, type of data, validity, data analysis, and outcomes. MERSQI produces a maximum score of 18 with a potential range from 5 to 18 . The maximum score for each domain is 3. The overall MERSQI scores pf the publications included in the review are shown in Table 1.

\section{Results}

A total of 2341 publications were screened, of which 297 were read in full text. Of these, 82 studies were excluded as not relevant. After the eligibility criteria of inclusion and exclusion were applied, a total of 26 studies were selected in the final data set for analysis (Fig. 1), with the majority (73\%) being clinical. Thirty-one percent of these were performed by consultant surgeons and $69 \%$ by surgical trainees in established surgical training programs. OCHRA as the only assessment method was used in 54\% of the 26 publications (Fig. 2).

OCHRA was applied to 719 surgical operations for direct analysis of the technical errors, hazard zones, external errors modes and P-GCs. The data also included a range of experimental research projects carried out by 265 surgical trainees, the vast majority of which used OCHRA with HRA being used only in 3 publications to evaluate surgical task performance.

Sixteen different surgical operations were analyzed using OCHRA: General Surgery, Colorectal Surgery, Bariatric Surgery, Urology, Ophthalmic Surgery, Pediatric Surgery, and Otorhinolaryngology. During execution of these operations, 7869 consequential errors were identified and analyzed (Table 1). Error rates and external error modes varied depending on the type of operations and level of experience of operators. In general, surgical trainees committed twice as many technical errors as specialist consultant/attending surgeons [16, 22].

The consequential error rate averaged 11 per procedure with a wide range of 4-34 (Table 1) depending on the complexity of the operation and level of expertise and skill of the operator. In one case series of 200 LCs [16], the inter-rater consistency of OCHRA was $85 \%$ and a strong correlation was observed between proficiency and error frequency upon test-re-test analysis $(r=0.79, P<0.001)$ [25]. In a similar 


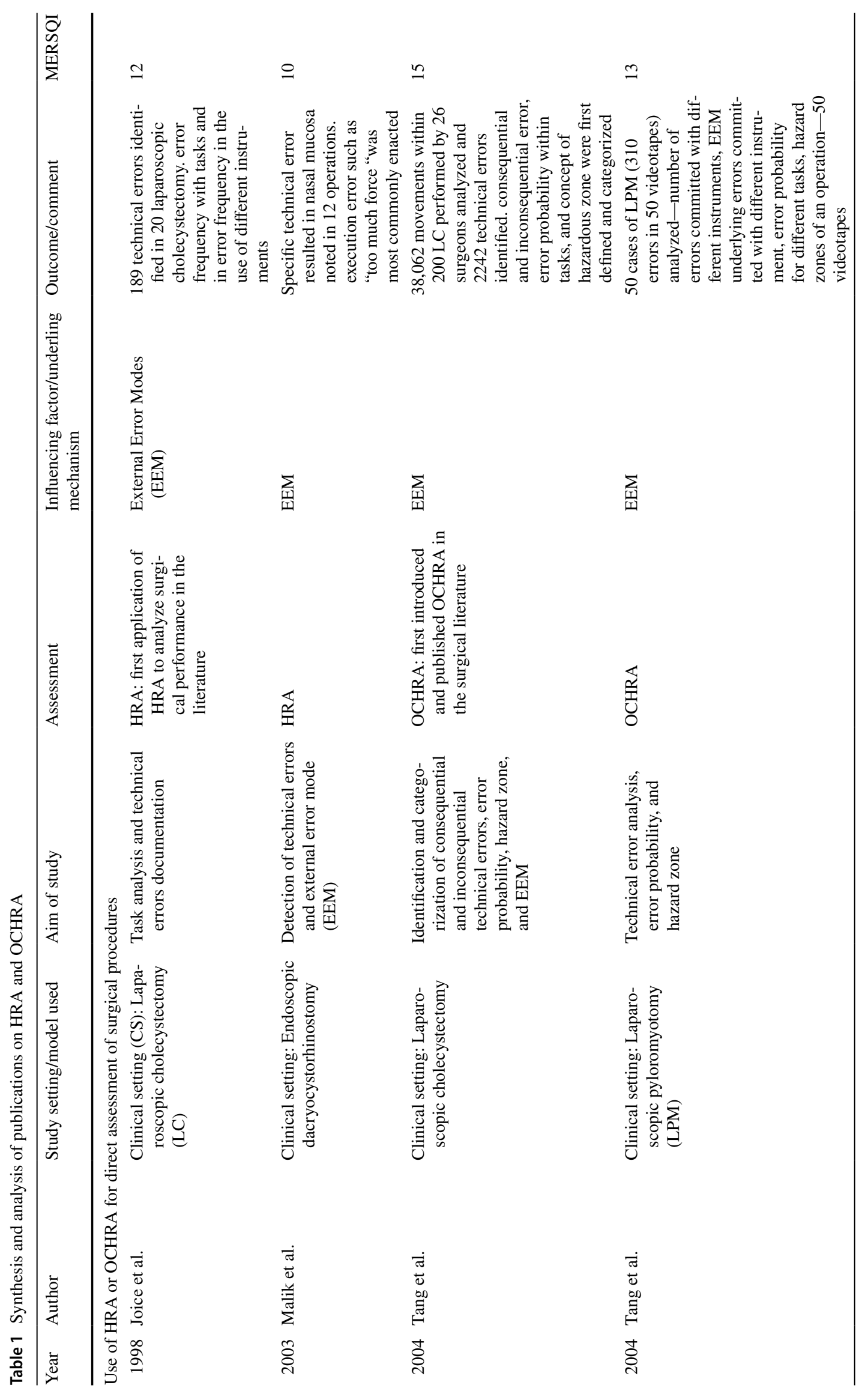




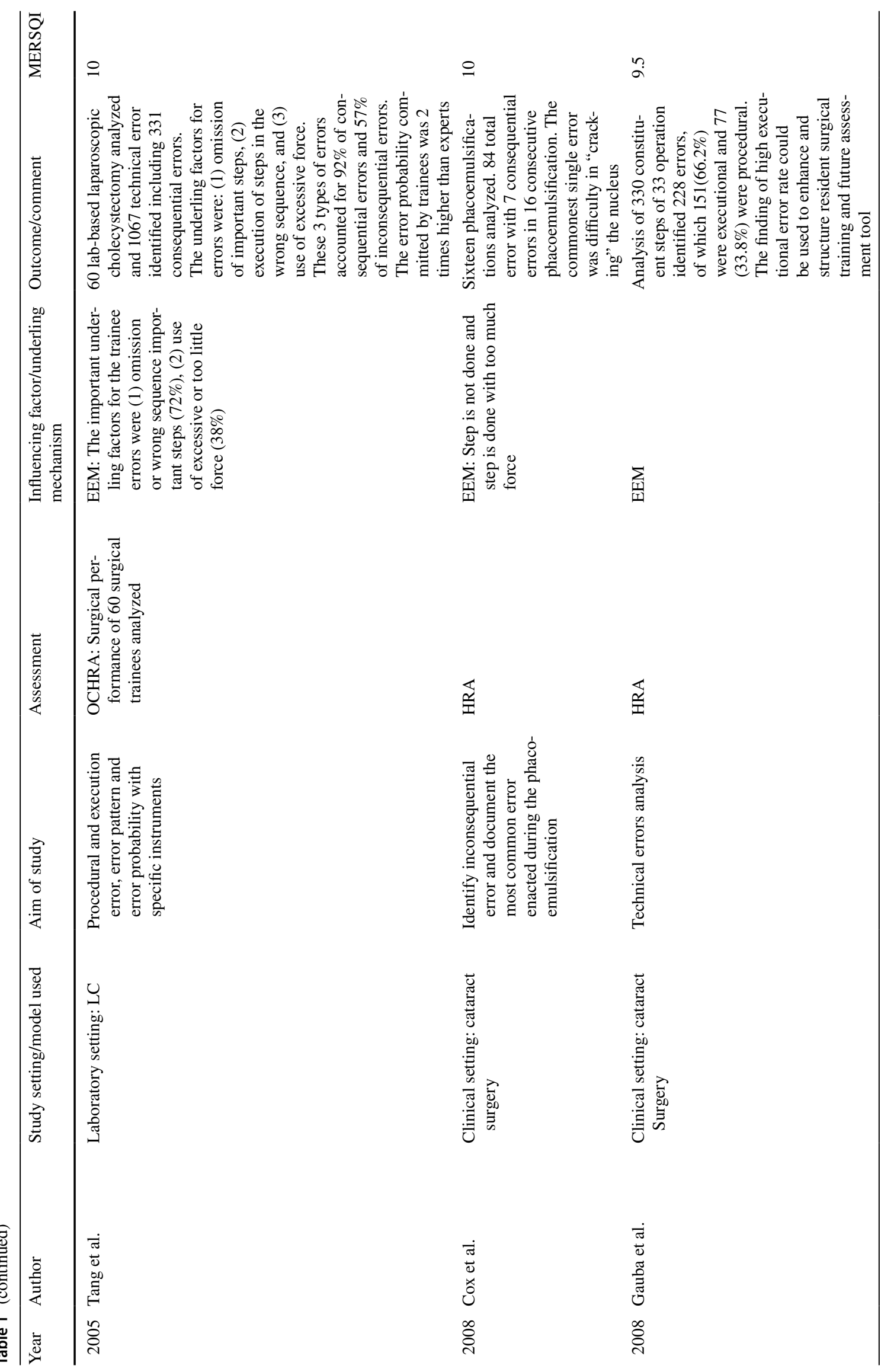




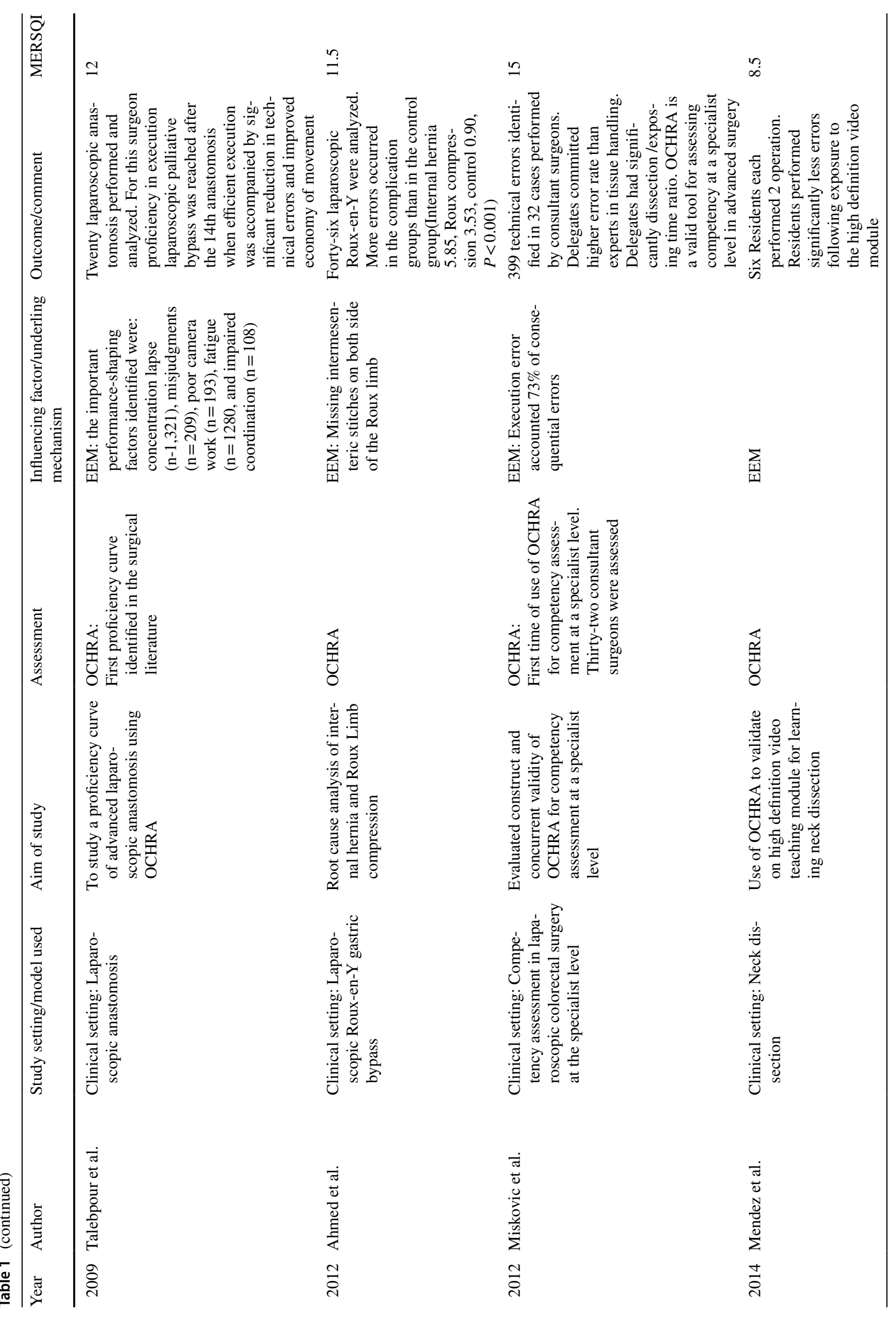




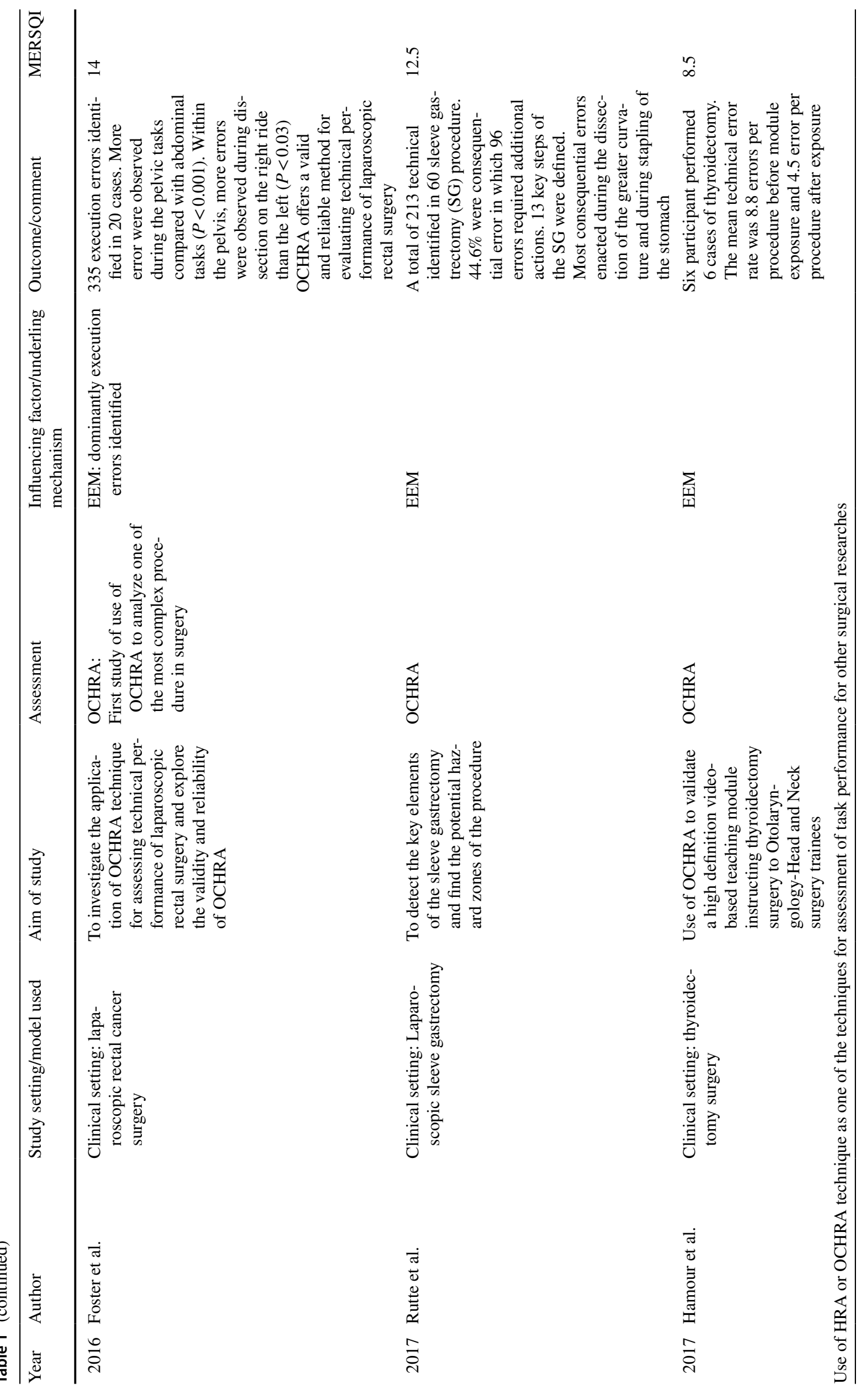




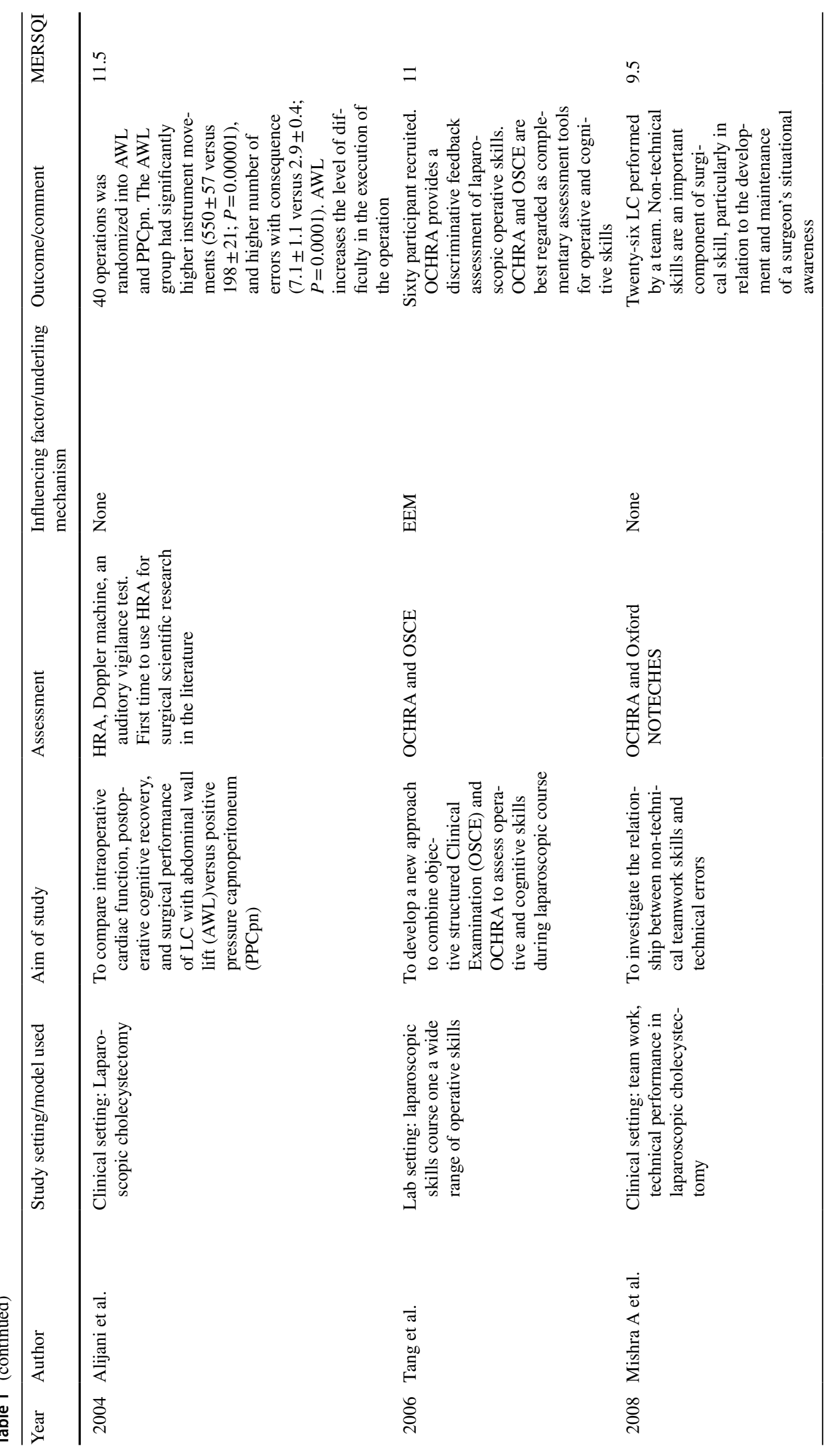




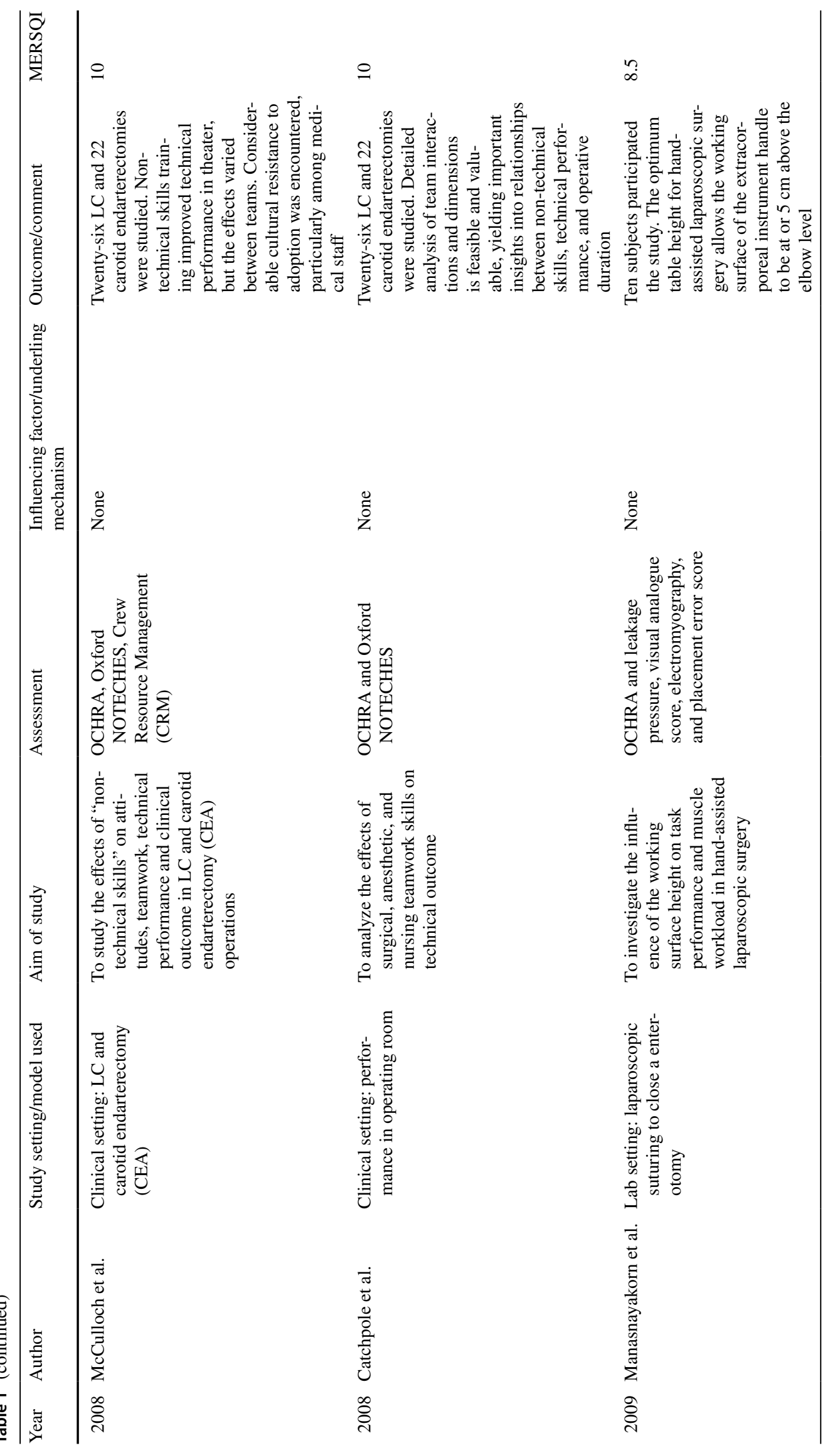




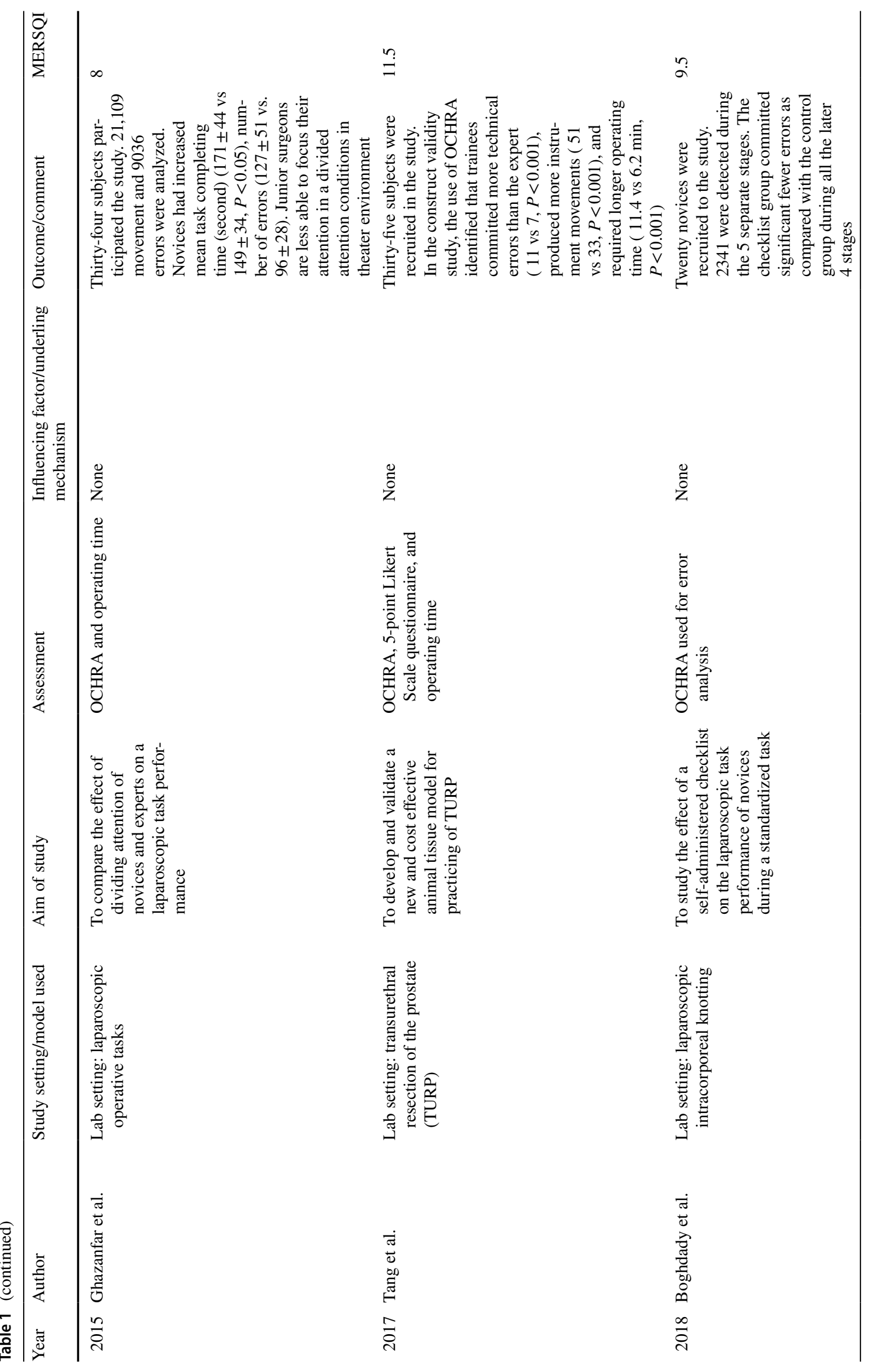




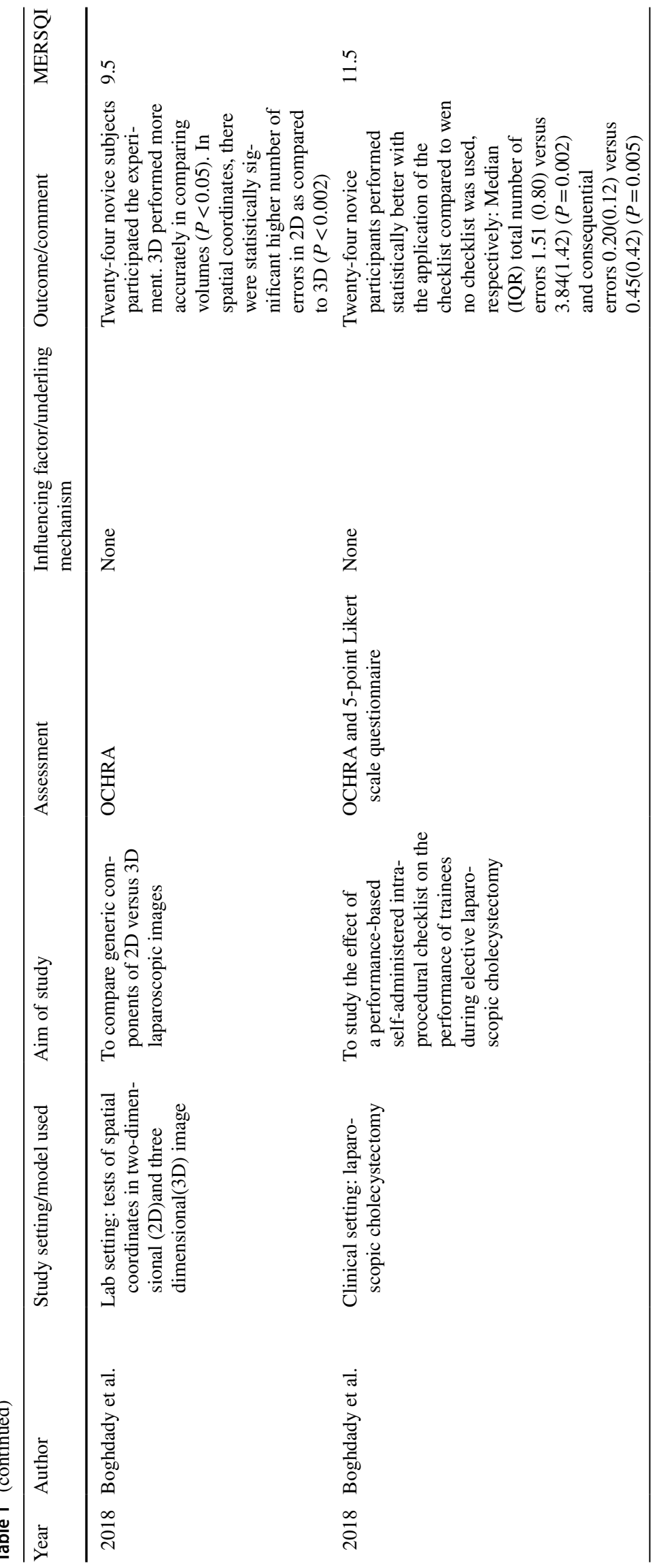




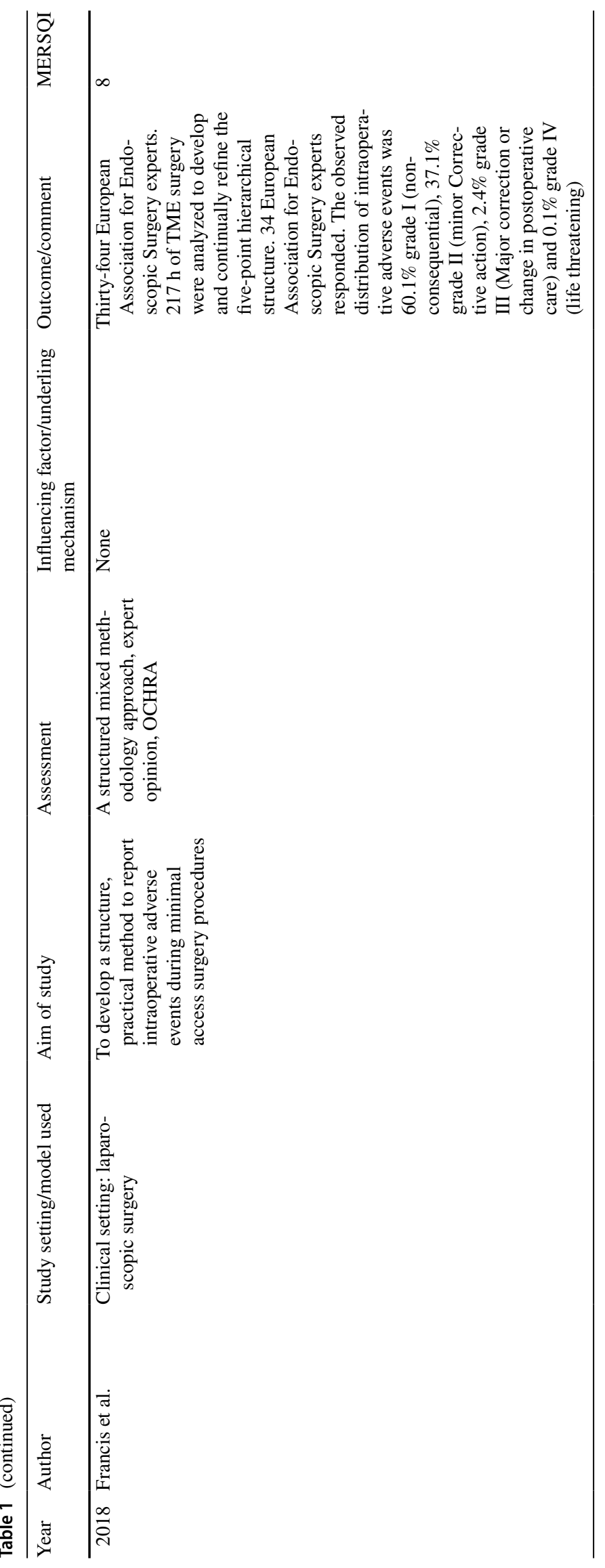


Fig. 2 Analysis of published studies included in review

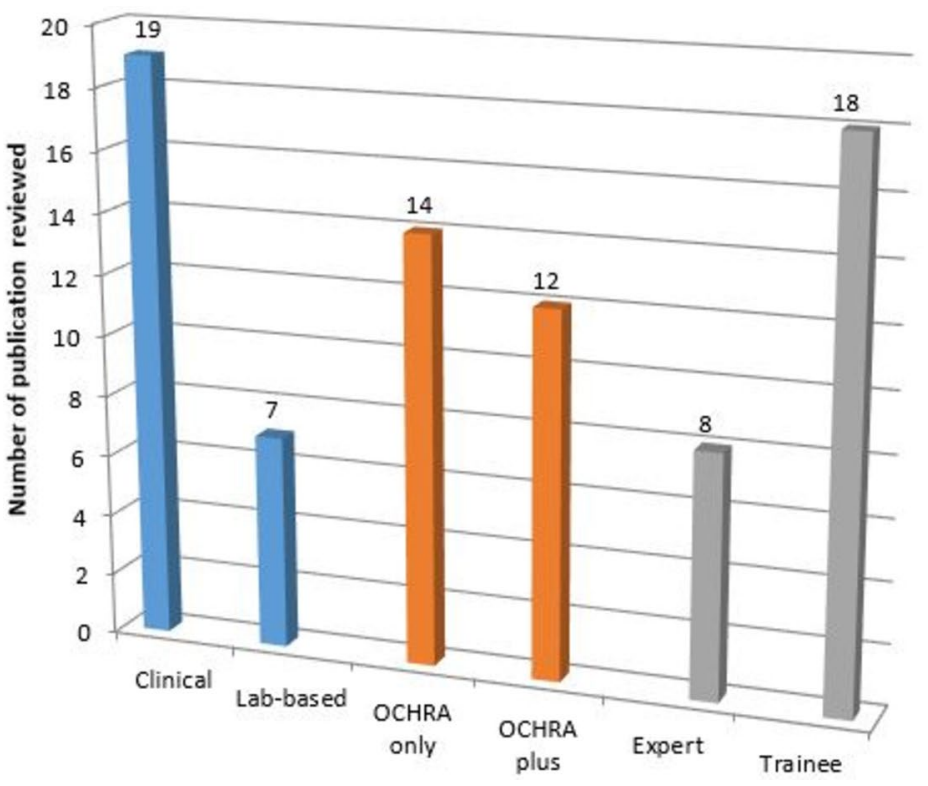

Assessment

nevel of participant study evaluating performance in advanced laparoscopic surgery, analysis of 335 execution errors showed a significant correlation between error frequency and mesorectal specimen quality $(R \mathrm{~s}=0.52, P=0.02)$ and with blood loss $(R \mathrm{~s}=0.609, P=0.004)$ [25]. Classification of intraoperative adverse events using OCHRA was agreed by $84 \%$ of 34 European Association for Endoscopic Surgery (EAES) experts in laparoscopic surgery [19]. Error rates and external error modes varied, depending on the type of operations and level of experience of operators. In general, surgical trainees committed twice the technical error rate than specialists [14, 22].

Only two publications reported on External Error Mode (EEM), both on laparoscopic colorectal resections. The first study reported on EEM at different levels of expertise and was based on 32 video-recorded laparoscopic colorectal resections, performed by experts and delegates of the National Training Program in England [28]. All included errors on tissue-handling, instrument-misuse, and times spent on dissecting (D) and exposure (E). This new performance variable was referred to as the $\mathrm{D} / \mathrm{E}$ ratio. Two independent expert surgeons globally assessed each video in terms of competency (pass vs. fail). The study identified 399 errors and reported significant differences between expert, pass, and fail candidates for total errors; with median errors for experts, pass, and fail candidates being 4, 10, and 17 $(P<0.001)$, respectively. Comparison between the pass and fail candidates showed more tissue-handling errors in the failed group ( 7 vs. $12 ; P=0.005$ ), but not for consequential and instrument-handling errors. As expected, the D/E ratio was significantly lower for delegates than for experts $(0.6$ vs. $1.0 ; P=0.001$ ) [28]. In this study all 4 independent variables were used to predict delegates who passed or failed the assessment, the area under the receiver operating characteristic curve was 0.867 , sensitivity $71.4 \%$, specificity $90.9 \%$, and overall predictive accuracy $84.4 \%$. Thus, OCHRA provides significant discriminative power (construct validity) between competent and non-competent performance [28].

The second, a single-center study, used OCHRA to identify technical errors enacted in unedited videos of 20 consecutive laparoscopic rectal cancer resections [25]. The study identified 335 execution errors with a median of 15/ operation. More errors were enacted during pelvic compared with abdominal steps $(P<0.001)$. Additionally, more errors were observed during dissection on the right than the left side of the pelvis $(P=0.03)$.

Hazard zones and difficult tasks were identified in all major commonly performed laparoscopic operations such as general surgical, colorectal, bariatric and ENT operations [16, 21, 25, 27, 29, 30, 32, 33]. Examples include dissection of triangle of Calot during LChole, dissection of right side of pelvis during laparoscopic resection of rectal cancer, mobilization of the greater curvature and stapling of the stomach during sleeve gastrectomy and access to nasal cavity during endoscopic dacryocystorhinostomy (DCR). Difficult tasks were also identified by OCHRA, e.g., intracorporeal sutured laparoscopic anastomosis and laparoscopic gastric bypass $[33,34]$.

The data also confirmed that OCHRA can be used to quantify the P-GC for a laparoscopic operation indicated by reaching the proficiency zone, when the individual surgeon attains maximal optimal performance in the execution of a specific procedure (Fig. 3) [34, 45]. It has also been suggested that OCHRA is a valid tool for assessing competency level in advanced specialist surgery, e.g., laparoscopic colorectal surgery $[23,25,28]$. 
Fig. 3 Attainment of proficient execution of palliative laparoscopic bilio-enteric bypass by surgical fellow (MT) indicating that this surgeon needed to perform 13 such procedures to reach a nadir of a few inconsequential operations [34]. Reproduced by permission of Editor in Chief/Publisher of Surgical Endoscopy

\section{Total number of errors per anastomosis}

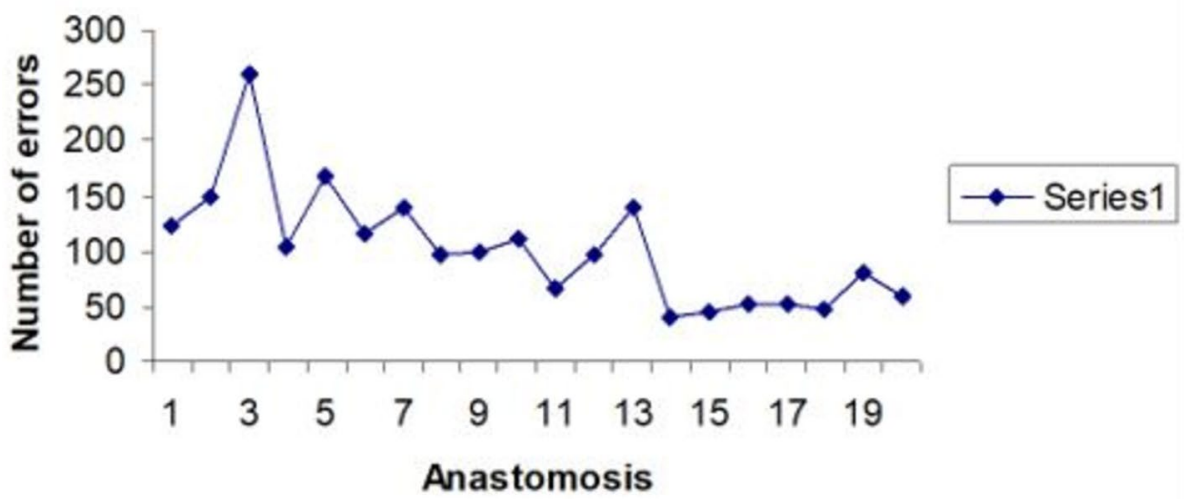

\section{Discussion}

OCHRA assesses the quality of execution by a surgeon (performance level) by detection and characterisation of technical errors (procedural/execution) and (consequential/inconsequential) enacted by the operator during the operation [16, 21-34]. In this process OCHRA, divides the continuum of an operation into steps, tasks and hazard zones, the last referring to sections of an operation where major errors, some catastrophic, iatrogenic injuries, occur most commonly [16, 21, 25-33].

The reported significant correlation between OCHRA error rates and quality of total mesorectal excision also confirms the clinical relevance of the technique in quality assessment of surgical performance [25, 28]. It also detects the attainment of complete proficiency reached by a surgeon indicated by a nadir of only a few inconsequential errors. This ability of OCHRA is currently underutilized in both surgical training and higher surgical specialization [22, 45-49].

In the OCHRA paradigm, technical errors are classified as consequential (need remedial action by surgeon) and inconsequential [16, 21, 22]. Any action or omission that causes an adverse event or increases the time of surgical procedure by necessitating a corrective action that falls outside the 'acceptable limits' constitutes a consequential error. Inconsequential errors are actions or omissions that increase likelihood of negative consequence and under slightly changed circumstances could result in an adverse effect on patient outcome. Inconsequential errors are important as they serve as 'near misses' providing key learning opportunities for reduction of future adverse events [11, 15-20].

Technical errors associated with inability of the surgeon to execute the component steps in the correct order are categorized as 'procedural error modes,' while 'execution error modes' reflect ineffective/traumatic manipulations
$[15,16,22]$. Surgical trainees committed twice the incidence of technical errors than consultant/attending surgeons [16, 22].

Underling mechanisms which provide a deeper understanding of the likelihood of occurrence of technical errors were reported in some studies, e.g., applying excessive force, incorrect order of steps, concentration lapses, misjudgements, poor instrument selection etc., have been identified as factors. Several hazard zones have also been described (Table 1) $[15,16,21,22,25-30]$ and difficult tasks highlighted [27, 34]. OCHRA enables differentiation between LCs and P-GCs. Learning an operation goes beyond cognitive knowledge, by the individual becoming able to execute the procedure safely, without having to think about it. In this process, the surgeon progresses from the controlled conscious mode (exhausting and cerebrally intensive and subject to fatigue) to the automatic mode, characterized by smooth effortless execution [49].

The study by Miskovic et al. which evaluated the performance of specialists executing live operations in the operating room, confirmed the validity of OCHRA in adjudicating surgical performance at a specialist level and suggested that this method could be implemented for competency assessment within a clinical training program [28]. Potentially, it can also be used for recertification and re-validation.

Equally important, the review highlights the current limitations of OCHRA including its labor-intensive nature involving human factors scientists using established criteria to identify and categorize errors from unedited videos of operations [15, 16, 21-42]. In this respect, the OCHRA will eventually benefit by progress in AI and ML [50]. This development is considered essential for the wider uptake of OCHRA. The review confirms that OCHRA by its documentation and characterisation of errors enacted by operator, constitutes a valid technique for objective assessment of competence in the execution of operations at both consultant and trainee levels (Fig. 4). 
Proficiency-gain curves (P-GCs) for majority of trainees ( $80 \%)$

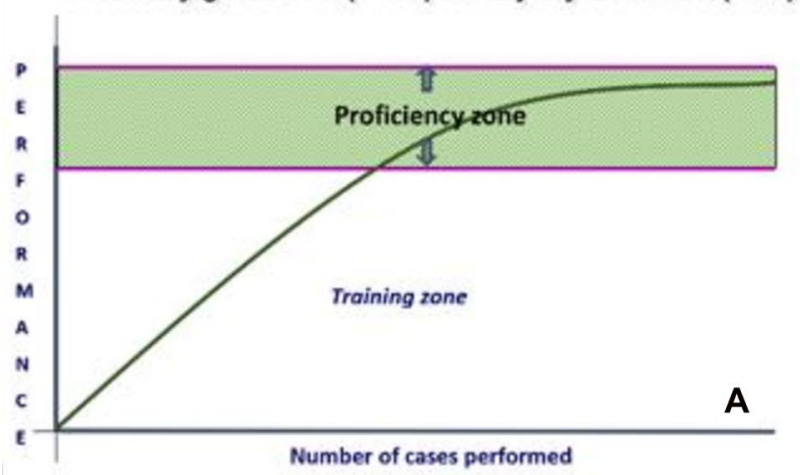

Negative P-GC for the surgically untrainable (12\%)

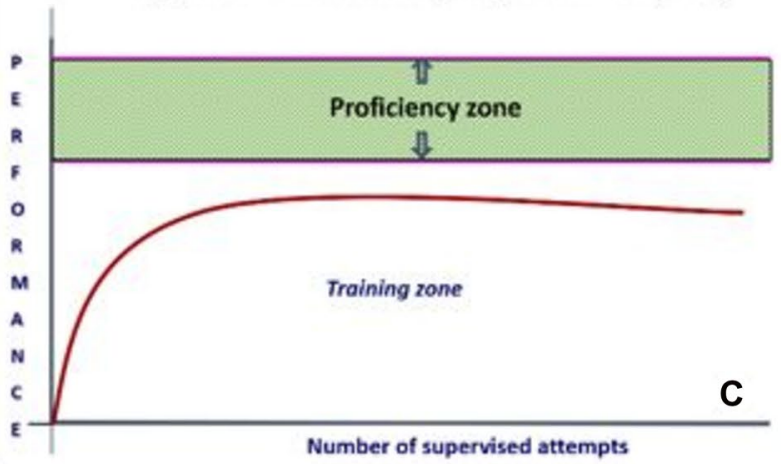

Fig. 4 Proficiency gain curves defined by OCHRA: A attainment of the proficiency zone by the majority of trainees $(80 \%)$ for a specific operation; B earlier attainment of the proficiency zone by naturally gifted trainees with high level innate aptitude for the same operation as in (A); $\mathbf{C}$ inability to reach the proficiency zone by surgically

\section{Conclusions}

The resulting increased uptake and use of OCHRA would enhance patient outcome after surgery in routine hospital surgical practice and surgical training, aside from being a useful tool for privileging, accreditation and re-validation. The low uptake of OCHRA despite its ability to assess execution quality of operations is attributed to its labor-intensive nature involving human factors (cognitive engineering) expertise. This issue can only be resolved by development of smart video recorders equipped with AI and ML based on incorporated and/or WIFI-accessible huge data sets of unedited recorded operations.

Author contributions Dr Benjie Tang was responsible for the design, acquisition, analysis, interpretation of data, drafting and revising for the work; Professor Sir Alfred Cuschieri contribute to conception of the work, analysis and interpretation of data for the work, revising the manuscript, approval of the final version of the review.

Funding There were no relevant financial relationships or any sources of support in the form of grants, equipment, or drugs.
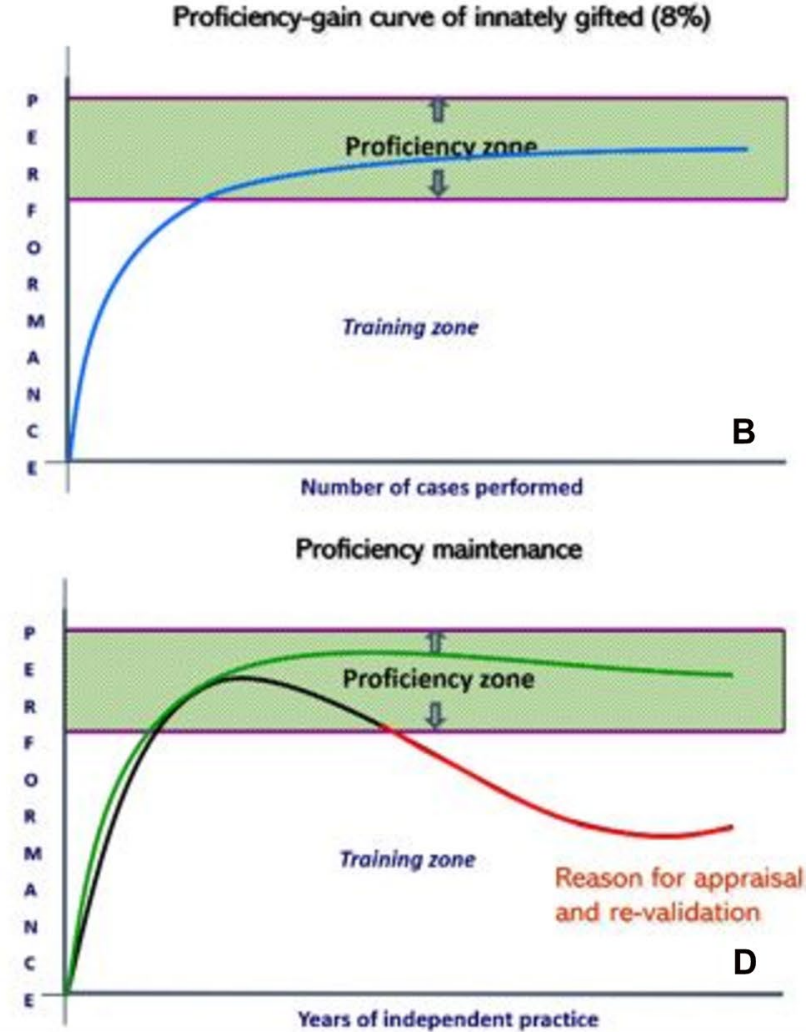

untrainable surgical trainees (11\%), who should be identified at an early stage and advised accordingly; D loss of proficiency by previously competent surgeons usually due to disease including alcoholism and other addiction

\section{Compliance with ethical standards}

Conflict of interest Dr Benjie Tang, Professor Sir Alfred Cuschieri have no conflict of interest in financial or personal relationships or affiliations that could influence (or bias) the author's decisions, work, or manuscript to disclose.

Open Access This article is licensed under a Creative Commons Attribution 4.0 International License, which permits use, sharing, adaptation, distribution and reproduction in any medium or format, as long as you give appropriate credit to the original author(s) and the source, provide a link to the Creative Commons licence, and indicate if changes were made. The images or other third party material in this article are included in the article's Creative Commons licence, unless indicated otherwise in a credit line to the material. If material is not included in the article's Creative Commons licence and your intended use is not permitted by statutory regulation or exceeds the permitted use, you will need to obtain permission directly from the copyright holder. To view a copy of this licence, visit http://creativecommons.org/licenses/by/4.0/.

\section{References}

1. Quirke P, Steele R, Monson J, Grieve R, Khanna S, Couture J, O'Callaghan C, Myint AS, Bessell E, Thompson LC, Parmar M, 
Stephens RJ, Sebag-Montefiore D, MRC CR07/NCIC-CTG CO16 Trial Investigators (2009) Effect of the plane of surgery achieved on local recurrence in patients with operable rectal cancer: a prospective study using data from the MRC CR07 and NCIC-CTG CO16 randomised clinical trial. Lancet 373(9666):821-828

2. Stevenson AR, Solomon MJ, Lumley JW, Hewett P, Clouston AD, Gebski VJ, Davies L, Wilson K, Hague W, Simes J, ALaCaRT Investigators (2015) Effect of laparoscopic-assisted resection vs open resection on pathological outcomes in rectal cancer: the ALaCaRT randomized clinical trial. JAMA 314(13):1356-1363. https://doi.org/10.1001/jama.2015.12009

3. Bridgewater B, Grayson AD, Au J, Hassan R, Dihmis WC, Munsch C, Waterworth P (2004) Improving mortality of coronary surgery over first four years of independent practice: retrospective examination of prospectively collected data from 15 surgeons. BMJ 329(7463):421

4. Dinçler S, Koller MT, Steurer J, Bachmann LM, Christen D, Buchmann P (2003) Multidimensional analysis of learning curves in laparoscopic sigmoid resection: eight-year results. Dis Colon Rectum 46(10):1371-1378

5. Hassan A, Pozzi M, Hamilton L (2000) New surgical procedures: can we minimise the learning curve? BMJ (Clin Res Ed) 320(7228):171-173

6. Sutton DN, Wayman J, Griffin SM (1998) Learning curve for oesophageal cancer surgery. Br J Surg 85(10):1399-1402

7. Guide to Patient Reported Outcome Measures (PROMs) (2019) https://digital.nhs.uk/data-and-information/data-tools-and-servi ces/data-services/patient-reported-outcome-measures-proms/ guide-to-patient-reported-outcome-measures-proms. Accessed 06 Aug 2019

8. Hudon P (2003) Applying the lessons of high risk industries to health care. Qual Saf Health Care 12(Suppl 1):i7-i12

9. Mishra A, Catchpole K, Dale T, McCulloch P (2008) The influence of non-technical performance on technical outcome in laparoscopic cholecystectomy. Surg Endosc 22:68-73

10. Ounounou E, Aydin A, Brunckhorst O, Khan MS, Dasgupta P, Ahmed K (2019) Nontechnical skills in surgery: a systematic review of current training modalities. J Surg Educ 76(1):14-24

11. Cuschieri A (2006) Nature of human error: implications for surgical practice. Ann Surg 244(5):642-648

12. Ubbink DT, Visser A, Gouma DJ, Goslings JC (2012) Registration of surgical adverse outcomes: a reliability study in a university hospital. BMJ Open 2(3):e000891

13. Martin RC, Brennan MF, Jaques DP (2002) Quality of complication reporting in the surgical literature. Ann Surg 235:803-813

14. Bruce J, Russell EM, Mollison J, Krukowski ZH (2002) The measurement and monitoring of surgical adverse events. Health Technol Assess 5(22):1-194

15. Joice P, Hanna GB, Cuschieri A (1998) Errors enacted during endoscopic surgery: a human reliability analysis. Appl Ergon 29(6):409-414

16. Tang B, Hanna GB, Joice P, Cuschieri A (2004) Identification and categorization of technical errors by observational clinical human reliability assessment (OCHRA) during laparoscopic cholecystectomy. Arch Surg 139:1215-1220

17. Cuschieri A, Tang B (2010) Human Reliability analysis (HRA) techniques and observational clinical HRA. MITAT 19(1):12-17

18. Kirwan B (1994) A guide to practical human reliability assessment. CRC Press, Boca Raton

19. Chandler FT, Chang YH, Mosleh J, Marble A, Julie L, Boring RL, Gertman DI (2006) Human reliability analysis methods: selection guidance for NASA. NASA/Office of Safety and Mission Assurance Technical Report, NASA, Washington, DC

20. Ujan MA, Habli I, Kelly TP, Guhnemann A, Pozzi S, Johnson CW (2017) How can healthcare organisations make and justify decisions about risk reduction? Lessons from a cross-industry review and a health care stakeholder consensus development process. Reliab Eng Syst Saf 161:1-11

21. Tang B, Hanna GB, Bax NMA, Cuschieri A (2004) Analysis of technical surgical errors during initial experience of laparoscopic pyloromyotomy by a group of Dutch pediatric surgeons. Surg Endosc 18:1716-1720

22. Tang B, Hanna GB, Cuschieri A (2005) Analysis of errors enacted by surgical trainees during skills training courses. Surgery 138:14-20

23. Francis NK, Curtis NJ, Conti JA, Foster JD, Bonjer HJ, Hanna GB, EAES Committees (2018) EAES classification of intraoperative adverse events in laparoscopic surgery. Surg Endosc 32:3822-3829

24. El Boghdady M, Alijani A (2018) The application of a performance-based self-administered intra-procedural checklist on surgical trainees during laparoscopic cholecystectomy. World J Surg 42:1695-1700

25. Foster JD, Miskovic D, Allison AS, Conti JA, Ockrim J, Cooper EJ, Hanna GB, Francis NK (2016) Application of objective clinical human reliability analysis (OCHRA) in assessment of technical performance in laparoscopic rectal cancer surgery. Tech Coloproctol 20:361-367

26. Mendez A, Seikaly H, Ansari K, Murphy R, Cote D (2014) High definition video teaching module for learning neck dissection. $\mathrm{J}$ Otolaryngol Head Neck Surg 43:7

27. van Rutte PWJ, Nienhuijs SW, Jakimowicz JJ, van Montfort G (2017) Identification of technical errors and hazard zones in sleeve gastrectomy using OCHRA. Surg Endosc 31:561-566

28. Miskovic D, Ni M, Wyles SM, Parvaiz A, Hanna GB (2012) Observational clinical human reliability analysis (OCHRA) for competency assessment in laparoscopic colorectal surgery at the specialist level. Surg Endosc 26(3):796-803

29. Gauba V, Tsangaris P, Tossounis C, Mitra A, McLean C, Saleh GM (2018) Human reliability analysis of cataract surgery. Arch Ophthalmol 126:173-177

30. Cox A, Dolan L, MacEwen CJ (2008) Human reliability analysis: a method to quantify errors in cataract surgery. Eye 22:394-397

31. Alijani A, Hanna GB, Cuschieri A (2004) Abdominal wall lift versus positive-pressure capnoperitoneum for laparoscopic cholecystectomy. Ann Surg 239:388-394

32. Malik R, White PS, Macewen CJ (2003) Using human reliability analysis to detect surgical errors in endoscopic DCR surgery. Clin Otolaryngol 28:456-460

33. Ahmed AR, Miskovic D, Vijayaseelan T, O’Malley W, Hanna GB (2012) Root cause analysis of internal hernia and Roux limb compression after laparoscopic Roux-en-Y gastric bypass using observational clinical human reliability assessment. Surg Obes Relat Dis 8:158-163

34. Talebpour M, Alijani A, Hanna GB, Moosa Z, Tang B, Cuschieri A (2009) Proficiency-gain curve for an advanced laparoscopic procedure defined by observational clinical human reliability assessment (OCHRA). Surg Endosc 23:869-875

35. Tang B, Hanna GB, Carter F, Adamson GD, Martindale JP, Cuschieri A (2006) Competence assessment of laparoscopic operative and cognitive skills: objective structured clinical examination (OSCE) or observational clinical human reliability assessment (OCHRA). World J Surg 30:527-534

36. McCulloch P, Mishra A, Handa A, Dale T, Hirst G, Catchpole K (2009) The effects of aviation-style non-technical skills training on technical performance and outcome in the operating theatre. Qual Saf Health Care 18:109-115

37. Catchople K, Mishra A, Handa A, McCulloch P (2008) Teamwork and error in the operating room: analysis of skills and roles. Ann Surg 247:669-706 
38. Mannasnayakorn S, Cuschieri A, Hanna GB (2009) Ergonomic assessment of optimum operating table height for hand-assisted laparoscopic surgery. Surg Endosc 23:783-789

39. Ghazanfar MA, Cook M, Tang B, Tait I, Alijani A (2015) The effect of divided attention on novices and experts in laparoscopic task performance. Surg Endosc 29(3):614-619. https://doi. org/10.1007/s00464-014-3708-2

40. Boghdady MEI, Ramakrishnan G, Tang B, Tait I, Alijani A (2018) A comparative study of generic visual components of two-dimensional versus three-dimensional laparoscopic images. World J Surg 42:688-694

41. Boghdady MEI, Tang B, Tait I, Alijani A (2016) The effect of a simple intraprocedural checklist on the task performance of laparoscopic novices. Am J Surg 214:373-377

42. Hou S, Ross G, Tait I, Halliday P, Tang B (2017) Development and validation of a novel and cost-effective animal tissue model for training transurethral resection of the prostate. J Surg Edu 74:898-905

43. Moher D, Liberati A, Tetzlaff J Altman DG; PRISMA Group (2009) Preferred reporting items for systematic reviews and metaanalyses: The PRISMA statement. BMJ 339:b2535

44. Reed DA, Cook DA, Beckman TJ, Levine RB, Kern DE, Wright SM (2007) Association between funding and quality of published medical education research. JAMA 298:1002-1009
45. Mackenzie H, Mikovic D, Ni M, Parvaiz A, Acheson AG, Jenkins JT, Griffith J, Coleman MG, Hanna GB (2013) Clinical and educational proficiency gain of supervised laparoscopic colorectal trainees. Surg Endosc 27:2704-2711

46. Hamour AF, Mendez AI, Harris JR, Biron VL, Seikaly H, Cote DWJ (2017) A high-definition video teaching module for thyroidectomy surgery. J Surg Educ 75:481-488

47. Ahmed K, Miskovic D, Darzi A, Athanasiou T, Hanna GB (2011) Observational tools for assessment of procedural skills: a systematic review. Am J Surg 202:469-480

48. DaRosa DA, Pugh CM (2011) Error training: missing link in surgical education. Surgery 151:139-145

49. Bargh JA (1992) The Ecology of automaticity: toward establishing the conditions needed to produce automatic processing effects. Am J Psychol 105(2):181-199

50. Hashimoto DA, Rosman G, Rus D, Meireles OR (2018) Artificial Intelligence in Surgery: Promises and Perils. Ann Surg 268(1):70-76

Publisher's Note Springer Nature remains neutral with regard to jurisdictional claims in published maps and institutional affiliations. 